\title{
28 Research Square \\ Epidemiological study of Rotavirus infection in the diarrheic neonatal calves
}

Z.M.A. Youssef ( $\nabla$ zeinabmohammed613@aun.edu.eg )

Assiut University

A.M.A. Zaitoun

Assiut University

\section{Research Article}

Keywords: Rotavirus, calves diarrhea, serological testing, Epidemiology

Posted Date: February 4th, 2022

DOl: https://doi.org/10.21203/rs.3.rs-1277218/v1

License: (9) (1) This work is licensed under a Creative Commons Attribution 4.0 International License. Read Full License

Version of Record: A version of this preprint was published at Acta Scientific Veterinary Sciences on February 17th, 2022. See the published version at https://doi.org/10.31080/ASVS.2022.04.0327. 


\section{Abstract \\ Background}

Neonatal diarrhea is the main cause of morbidity and mortality in calves, and Rotavirus is the main viral etiology. The objective of the current study was to study the epidemiological role of Rotavirus infection in diarrheic neonatal cattle and buffaloes 'calves in Assiut Governorate, Egypt. From December 2015 to November 2019, a total number of 315 neonatal calves' belonged to different localities of Assiut Governorate, Upper Egypt, were clinically examined. Fecal samples of investigated calves were subsequently collected and serologically tested to reveal-up Rotavirus infection by using latex agglutination test (LAT) and immunochrmatographic assay (ICA).

\section{Results}

The seropositive samples by LAT and ICA were $16.74 \%$ and $8.54 \%$, respectively. The clinical findings of Rotavirus infection in enteric calves were pointed. The percentage of Rotavirus infection was $14.92 \%(44 / 295)$ of clinically diarrheic calves. However, $10 \%(2 / 20)$ of apparently healthy calves $(n=20)$ harbor Rotavirus in their feces suggesting carrier status. The high percentage of Rotavirus infection (20.13\%) was obviously observed in 3 days-4 weeks old calves. There were no significance differences $(P<0.05)$ between the percentages of Rotavirus infection and sex, species (cattle and buffaloes) and breed (Native and Cross breed) of serologically tested calves. Moreover, there is no significant variations $(p<0.05)$ between calves under farmer's hand and calves bred in farm in susceptibility to Rotavirus infection. Based on climatologic conditions of Assiut, seropositive cases were more prevalent $(P<0.001)$ in cold months $(22.67 \%)$ than the warm and hot months (7.27\%) in Assiut.

\section{Conclusion}

Rotavirus plays an outstanding role in causing enteritis in calves during neonatal stages in different localities of Assiut. Vaccination program of pregnant dams and lactogenic immunity in calves against Rotavirus infection should be warranted.

\section{Background}

Neonatal enteritis appears to be a major problem of calves' rearing causing a considerable level of economic losses [1]. Escherichia coli is frequently incriminated as an outstanding pathogen causing enteritis in neonatal cattle and buffaloes calves [2]. However, there are many pathogens were implicated as pathogens-causing enteritis in neonatal calves. Enteric viral infections particularly Rotavirus and Coronavirus infection cause acute viral enteritis [3,4]. Rotavirus is more prevalent $(P>0.01)$ than Coronavirus [5]. Rotavirus causes intestinal villous atrophy inducing maldigestion followed by malabsorption [6] with colossal economic losses of infected calves. Practically, diagnosis of Rotavirus infection in enteric neonatal calves based on clinical background in association with serological testing using LAT and ICA as field rapid tests [15]. Epidemiological data of Escherichia coli enteritis of neonatal calves was previously documented [2]. Inversely, reviewing of 
available literature indicated that epidemiological data of Rotavirus infection in diarrheic neonatal calves appears to be scarce. Consequently, the current work was carried-out to clear-up the epidemiological role of Rotavirus infection in diarrheic neonatal cattle and buffaloes' calves.

\section{Results}

\section{Clinical findings}

Clinical findings revealed that the enteric calves showed classic signs of enteritis. Diarrhea, dehydration, weakness, reluctance to move, recumbence, unable to stand and signs of comatose were observed. The severe cases had emaciated with straining and arched back. Fecal discharges of enteric calves were varies from watery to pasty in consistency and varied from yellowish to greenish. Fecal samples contained mucus with or without undigested food.

\section{Serological diagnosis}

LAT indicated that 39 (16.74\%) of 233 examined samples were serologically positive. ICA revealed that 7 (8.54\%) of 82 tested fecal samples were serologically positive (Table 1$)$.

\section{Epidemiological findings}

\section{Percentage of Rotavirus infection}

The present study indicated that percentage of Rotavirus infection was $14.60 \%(46 / 315)$ of examined calves (Table 2). The percentage of Rotavirus infection among enteric calves was $14.92 \%(44 / 295)$ and $10 \%$ $(2 / 20)$ among clinically healthy calves (Table 2$)$. Regarding to locality, infection of Rotavirus was $15.20 \%$ ( 26 of 171) of fecal samples collected from calves that came to Veterinary Teaching Hospital, and was $13.89 \%$ (20 of 144) of tested fecal samples of calves of farms in Assiut Governorate (Table 3).

\section{Age susceptibility}

The rate of Rotavirus infection was studied in calves at age groups of 3 days-4 week, 5-8 weeks and 9-12 weeks and yielding $20.13 \%, 9.45 \%$ and $10.27 \%$, respectively of 315 of examined calves. The highest of Rotavirus infection was observed at age group 3 days-4 week (Table 4 and Figure 1).

\section{Effect of sex}

The analytic results indicated that there was no significant difference in percentage of Rotavirus infection between male and female calves (Table 5).

\section{Species susceptibility}

Rotavirus infection was diagnosed in cattle and buffalo calves' fecal samples. The results revealed that $15.83 \%$ and $5.41 \%$ of cattle and buffaloes calves were positive, respectively (Table 6).

\section{Breed susceptibility}


In the present study, there was no significant difference in percentage of Rotavirus infection between Native and Cross breeds (Table 7).

\section{Seasonal variation}

The obtained indicated that the percentage of Rotavirus infection in examined calves was higher in cold months $(22.67 \%)$ than $(7.27 \%)$ in warm and hot months (Table 8$)$.

\section{Discussion}

Neonatal calf enteritis is a multifactorial syndrome due to interaction between immune status of calves, environment, management, nutrition beside enteropathogens. The later appear to be the cornerstone of neonatal enteritis when the hygienic measures were sublevel [1]. The current work indicated the percentage of Rotavirus infection in enteric neonatal calves was $14.92 \%$ and the majority of serologically positive cases were occurred during the neonatal stage (3 days-4 weeks post parturition) referring to Rotavirus infection is neonates-linked-disease. However, the current serological examinations revealed that $10.27 \%$ of the serologically tested calves (9-12 weeks in age) was harbored Rotavirus in their feces. From clinical point of view, the current work revealed that Rotavirus infection was serologically positive in 46 cases. Watery to pasty yellowish diarrhea followed by dehydration was the prominent clinical findings. Similar findings were previously reported by $[3,8,9]$.

Serologically, LAT and ICA are rapid and easy diagnostic tests keeping laboratory viral detection is convenient and simplistic [1]. The current serological tests indicated that $16.74 \%$ of fecal samples of examined calves were positive by LAT and this result was higher than result obtained previously $[10,11]$ that indicated that rate of serologically positive calves to Rotavirus infection was $6.76 \%$ and $10.83 \%$, respectively. Highest rate of Rotavirus infection were reported previously [3,5] and concluded that the serologically positive cases reached-up to $21.43 \%$. The present study showed that 7 (8.54\%) of 82 diarrheic fecal samples of investigated calves were positive by ICA. Our result of ICA was lower than those of other studies $[1,12,13]$ in which rate of Rotavirus infection in serologically positive enteric calves by ICA was $15.63 \%, 12.50 \%$ and $10 \%$, respectively.

Epidemiologically, the present study found that percentage of Rotavirus infection of examined calves was $14.60 \%$ in Assiut Governorate. Previously, the high rate of Rotavirus infection in calves in Assiut was reported [3]. Such variation may be due to difference factors elucidated by [9]. However, the sublevel of hygienic measures plays an important role in prevalence of enteropathogens [3]. In the current work, Rotavirus infection was serologically detected in enteric (14.92\%) and apparently healthy (10\%) calves. The occurrence and distribution of Rotavirus were studied in enteric and clinically healthy calves [3]. The high rate of Rotavirus infection in enteric neonatal calves rather than healthy cases may be ascribed to Rotavirus destroys the enterocytes of small intestine leading to diarrhea, which is followed by a profuse fecal shedding of virus. Regarding to locality in the present study, there was no significant difference in percentage of Rotavirus infection in examined calves of Veterinary Teaching Hospital and farms of Assiut Governorate. This may be attributed to investigated calves were found under the same geographical, seasonal condition, hygienic measures and method of animals rearing. Statistical analysis of the obtained results 
showed that the rate of infection with Rotavirus was decreased by increasing the age of the examined calves and the peak of infection was at 3 days- 4 weeks old. The rate of Rotavirus infection in calves was recorded at variant ages and results of other study concluded that rate of infection with Rotavirus was highest during the first 2 week and thereafter declining by increasing the age of calves [11]. This may be due to immune system of neonatal calves is not fully mature to handle Rotavirus pathogen and susceptibility of calves to Rotavirus decreases with age probably due to loss of receptors on enterocytes[11,14].

In referring to the effect of sex on distribution of Rotavirus infection, there was no significant difference in rate of Rotavirus infection between male and female calves the statistically. This may indicate that Rotavirus is non-sex-linked disease. Concerning to species susceptibility, the obtained results revealed that Rotavirus infection was diagnosed in both cattle and buffalo calves' fecal samples with no significant difference, although mathematically the higher percentage of Rotavirus infection in cattle's calves than buffalo calves. These findings were previously recorded [11] in which the susceptibility of cattle's calves to be infected with Rotavirus was higher than buffalo's calves and this may relate to difference of natural immunity of the two different species.

In the present work, there was no significant difference in percentage of Rotavirus infection between Native and Cross breeds but mathematically Cross breed had higher rate than Native breed. This finding was similar to [3] that concluded that there was no significant difference in prevalence of Rotavirus infection between different breeds of calves. The higher percentages of cross breed to Rotavirus infection in our result may be due to differences in digestive efficiency of absorption of antibodies in colostrum between different breeds beside differences in amounts of digestive enzymes, so suggests breed difference in susceptibility to Rotavirus infection [15]. Relationship between seasonal variations and rate of Rotavirus infection was studied and found that the percentage of infection was significantly higher in cold months (22.67\%) than warm and hot months $(7.27 \%)$. Similar results were reported by $[4,8,11]$. In Egypt, most calving occurs at the end of autumn and beginning of winter in which these neonatal calves are more susceptible to Rotavirus infection. Increased risk of Rotavirus infection during cold months may be attributed to the increased survivability of virus at low relative humidity and temperature. Additionally, the titer of immunoglobulins such as $\lg A$, IgM and IgG in colostrum which act as protective factor against such infection in calves was decreased in autumn, winter and increased during spring, summer $[4,8]$.

\section{Conclusions}

Rotavirus plays an outstanding role in neonatal calves' enteritis in different localities of Assiut governorate. LAT and ICA are reliable serological tests for detection of Rotavirus infection. Rotavirus infection is more prevalent in neonatal age group (3 days - 4 weeks). There were no significance difference in Rotavirus infection and sex, species and breed of examined calves. The higher percentage of Rotavirus infection was recorded in cold months than warm and hot months.

\section{Methods}

\section{Animals}


During the period of investigation, December 2015 to November 2019, a total number of 315 neonatal calves of different ages, sex, species and breed were subsequently examined clinically at Veterinary Teaching Hospital, Faculty of Veterinary Medicine, Assiut University according to [7].

\section{Sampling}

Fecal samples of the enteric calves were collected and serologically tested. Moreover, fecal samples of random selection of apparently healthy neonatal calves were also collected and serologically tested.

\section{Serological diagnosis}

Serological screening of Rotavirus antigen in the collected samples was carried-out by two tests; LAT and ICA. Two-hindered thirty-three fecal samples were tested by LAT, a commercial kit (REF-M80 Rotascreen ${ }^{\circledR}$ kit Microgen Bioproducts limited, United Kingdom) and 82 samples tested by ICA (Rotascreen® Dipstick M580, Microgen Bioproducts limited, United Kingdom and Atlas Medical, United Kingdom). The serotesting was carried-out as per the manufacturer's instructions.

\section{Statistical analysis}

The collected epidemiological data were enrolled and analyzed by Chi-square of independence according to Statistical package for the social sciences (SPSS) version 16 software program (2007).

\section{Declarations}

\section{Acknowledgements}

The authors thank the veterinarians and farm owners for their support and help in providing data and samples collection throughout the study.

\section{Authors' contributions}

Z.M.A. Youssef and A.M.A. Zaitoun performed the outline of the study, analyzed and interpreted the data regarding the examination, and were a major contributor in writing and revision the manuscript. All authors read and approved the final manuscript.

\section{Funding}

Not applicable.

\section{Availability of data and materials}

The datasets used and/or analyzed during the current study are not currently available because they contain information that might breach respondent confidentiality but are available from the corresponding author on reasonable request.

\section{Competing interests}


The authors declare that they have no competing interests.

\section{Ethics Approval}

Not applicable.

\section{Consent to participate}

Not applicable.

\section{Consent for publication}

Not applicable.

\section{Author details}

Infectious diseases, Department of Animal Medicine, Faculty of Veterinary Medicine, Assiut University, Egypt.

\section{References}

1. Barua SR, Islam S, Siddiki AMAMZ, Masuduzzaman M, Hossain MA, Chowdhury S. Comparison of diagnostic tests for detection of bovine Rotavirus A in calf feces. Mac Vet Rev. 2021; 44(1): i-ix.

2. Awad WS, El-Sayed AA, Mohammed FF, Bakry NM, Abdou NMI, Kamel MS. Molecular characterization of pathogenic Escherichia coli isolated from diarrheic and in-contact cattle and buffalo calves. Trop Anim Health Prod. 2020; 52(6): 3173-3185.

3. Zaitoun AMA, Abdel-Hakim O, Youssef ZMA. Enteric Rota and Corona viruses' infection in calves. Assiut Vet Med J. 2018; 64(156): 8-17.

4. Singh S, Singh R, Singh KP, Singh V, Malik YPS, Kamdi B, et al. Epidemiological study of naturally occurring bovine Rotavirus infection in organized dairy farms, India. Biol Rhythm Res. 2019. p. 1-9.

5. Youssef ZMAM. Enteric Rota and Corona viruses infection in neonatal calves. MVSc, Thesis, Faculty of Veterinary Medicine, Assiut University, Egypt. 2017.

6. Brown CC, Baker DC, Barker LK. The Alimentary tract. In Jubb, Kennedy and Palmer's of Domestic Animals, Edited by Grant Maxie. 5 ${ }^{\text {th }}$ Edition. Vol. II, chapter 1.Sunders LTD. 2007. p. 69-130.

7. Jackson PGG, Cockcroft PD. Clinical examination of farm animals. $1^{\text {st }}$ Edition. United Status of America. 2002. p. 95-101.

8. Barua SR. Clinico-pathology and Molecular characterization of bovine Rotavirus infection in calves in south-eastern part of Bangladesh. PhD, Thesis, Faculty of Veterinary Medicine, Chittagong Veterinary and Animal Sciences University, Bangladesh. 2019

9. Hossain MB, Rahman MS, Watson OJ, Islam A, Rahman S, Hasan R, et al. Epidemiology and genotypes of group A Rotaviruses in cattle and goats of Bangladesh, 2009-2010. Infect Genet Evol. 2020. p. 1-29.

10. Dulgheroff ACB, Pereira WAB, Sarmento RR, Silva GAV, Naveca FG, Domingues ALS. Analysis of bovine Rotavirus strains circulating in diarrheic dairy calves in Uberaba, Minas Gerais, Brazil, during 2008-2009. Arq Bras Med Vet Zootec. 2016; 68(4): 1090-1094. 
11. Makwana PM, Kalyani IH, Desai D, Patel JM, Solanki JB, Vihol PD, et al. Detection of bovine Rotavirus (BRV) infection in neonatal calves of in and around Navsari district of South Gujarat, India. J Entomol Zool Stud. 2020; 8(2): 1092-1097.

12. Sakli GU, Bulut O, Hasöksüz M, Hadimli HH. Investigation of bovine Coronavirus and bovine Rotavirus by rapid diagnosis kit and RT-PCR in diarrheic calf feces. J Istanbul Vet Sci. 2019; 3(3): 57-63.

13. Babalola MO. Group A Rotavirus genotypes among calf herds in Southwest Nigeria and implications for human Rotavirus vaccines' efficiency. Open J Vet Med. 2020; 10: 1-13.

14. Geletu US, Bari FD, Usmael MA, Tesfaye A. Isolation and Characterization of Coronavirus and Rotavirus Associated With Calves, in Central Part of Oromia, Ethiopia. Res Sq. 2020. p. 1-23.

15. Youssef ZMAM. Molecular Detection and Typing of Rotavirus causing Enteritis in neonatal Bovine and Bubaline calves. PhD, Thesis, Faculty of Veterinary Medicine, Assiut University, Egypt. 2021

\section{Tables}

Table 1. Serological detection of Rotavirus in the examined calves by LAT and ICA $(n=315)$

\begin{tabular}{|l|c|c|c|}
\hline Serological test & Number of animal & Positive & $\%$ \\
\hline LAT & 233 & 39 & 16.74 \\
\hline ICA & 82 & 7 & 8.54 \\
\hline Total & 315 & 46 & 14.60 \\
\hline
\end{tabular}

Table 2. Percentage of Rotavirus infection in enteric and apparently healthy calves

\begin{tabular}{|l|c|c|c|}
\hline Calves & No. & Positive & $\%$ \\
\hline Enteric calves & 295 & 44 & 14.92 \\
\hline Apparently healthy calves & 20 & 2 & 10 \\
\hline Total & 315 & 46 & 14.60 \\
\hline
\end{tabular}

$\mathrm{P}$ value $=0.363$. No significant variation at $\mathrm{p}<0.05(0.547)$

Table 3. Distribution of Rotavirus infection among the examined calves

\begin{tabular}{|l|c|r|c|}
\hline Origin & No. & Positive & $\%$ \\
\hline Private cases* & 171 & 26 & 15.20 \\
\hline Farms & 144 & 20 & 13.89 \\
\hline Total & 315 & 46 & 14.60 \\
\hline
\end{tabular}

* Admitted from various villages of Assiut to The Veterinary Teaching Hospital, $\mathrm{P}$ value $=0.109$. No significant variation at $\mathrm{p}<0.05(0.742)$. 
Table 4. Age susceptibility to Rotavirus infection of investigated calves

\begin{tabular}{|l|c|c|c|}
\hline Age groups & No. & Positive & $\%$ \\
\hline 3 days-4 weeks & 149 & 30 & $20.13 *$ \\
\hline 5-8 weeks & 127 & 12 & 9.45 \\
\hline 9-12 weeks & 39 & 4 & 10.27 \\
\hline Total & 315 & 46 & 14.60 \\
\hline
\end{tabular}

$\mathrm{P}$ value $=6.952 *$ Significant increase at $\mathrm{p}<0.05(0.031)$

Table 5. Effect of sex on Rotavirus infection of examined calves

\begin{tabular}{|l|c|c|c|}
\hline Sex & No. & Positive & $\%$ \\
\hline Male & 181 & 31 & 17.13 \\
\hline Female & 134 & 15 & 11.19 \\
\hline Total & 315 & 46 & 14.60 \\
\hline
\end{tabular}

$\mathrm{P}$ value $=2.173$. No significant variation at $\mathrm{p}<0.05(0.140)$.

Table 6. Species susceptibility and Rotavirus infection of the investigated calves

\begin{tabular}{|l|c|c|c|}
\hline Species & No. & Positive & $\%$ \\
\hline Cattle calves & 278 & 44 & 15.83 \\
\hline Buffalo calves & 37 & 2 & 5.41 \\
\hline Total & 315 & 46 & 14.60 \\
\hline
\end{tabular}

$\mathrm{P}$ value $=2.844$. No significant variation at $\mathrm{p}<0.05(0.09)$.

Table 7. Breed susceptibility and Rotavirus infection of the examined calves

\begin{tabular}{|l|c|c|c|}
\hline Breed & No. & Positive & $\%$ \\
\hline Native (baldy) & 113 & 14 & 12.39 \\
\hline Cross breed (Frisian/native) & 202 & 32 & 15.84 \\
\hline Total & 315 & 46 & 14.60 \\
\hline
\end{tabular}

$P$ value $=0.693$. No significant variation at $p<0.05(0.405)$.

Table 8. Seasonal variations and Rotavirus infection of the investigated calves 


\begin{tabular}{|l|c|c|c|}
\hline Seasons & No. & Positive & $\%$ \\
\hline Cold months (November-February) & 150 & 34 & $22.67 * *$ \\
\hline Warm and Hot months (March-October) & 165 & 12 & 7.27 \\
\hline Total & 315 & 46 & 14.60 \\
\hline
\end{tabular}

$\mathrm{P}$ value $=14.931 \quad * * *$ highly significant increase at $\mathrm{p}<0.001(0.000)$.

\section{Figures}

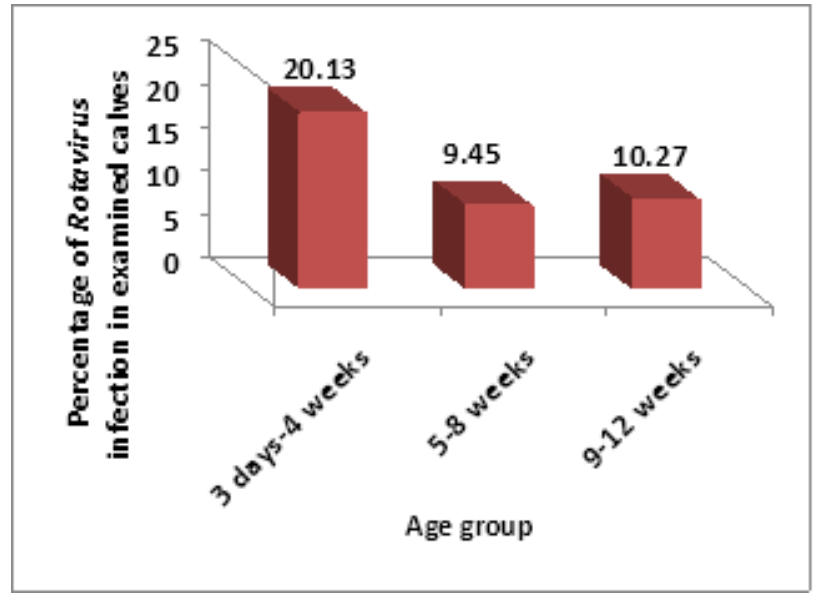

Figure 1

Age susceptibility to Rotavirus infection in investigated calves. 